Bull. Fac. Agric., Cairo Univ.,64:389-395 (2013).

\title{
KINETICS OF PHYTIC ACID DEGRADATION IN TWO ACCESSIONS OF VELVET BEANS TREATED BY UV RADIATION
}

(Received:25.11.2013)

\author{
M. S. Al-Rawashdeh, G. J. Al-Rabadi, Nofal Al-Ameiri*， Veerabahu Ramasamy Mohan** \\ Department of Animal Production, Faculty of Agriculture, Mutah University, Al-Karak, Jordan. \\ *Department of Protection and Integrated Pest Management, Faculty of Agriculture, \\ Mutah University, Al-Karak, Jordan. **Ethnopharmacology Unit, Research Department of Botany, \\ V.O.Chidambaram College, Tuticorin-628008, Tamil Nadu, India
}

\begin{abstract}
The influence of UV radiation on the kinetics of phytic acid degradation in the seeds of two accessions (black colored and white colored seed coat) of velvet bean (soaked and unsoaked) were examined. Data of the resulting phytic acid degradation rate were well fitted by simple zero-order kinetics with correlation value $\left(r^{2}\right)$ range 0.94-0.99. A linear correlation suggest that the initial high concentration of phytic acid will not increase the rate of phytic acid degradation after being exposed to UV radiation. For each accession, phytic acid degradation rate of the seeds was always higher than that of unsoaked seeds. In addition, the phytic acid degradation rate was always higher for black colored seed coat seeds than white colored seed coat seeds. Phytic acid in both accessions of velvet bean seems not to be the influential factor in determining its maximum inclusion level used in poultry diets.
\end{abstract}

Key words: phytic acid; soaking; UV radiation; velvet beans; zero-order kinetics

\section{INTRODUCTION}

Velvet bean is widely grown and is cultivated extensively in many countries worldwide (Buckles, 1995; Ezeagu et al., 2003). Velvet bean has high surviveal ability due to its resistantce to insects and drought. It can be managed with least care, and reported to enhance soil fertility through the ability of nitrogen fixation (Ferriera et al., 2003). From nutritional prospective, velvet bean can be fed to both ruminant (Liener, 1994) and mono gastric animals such as poultry (Olaboro et al., 1991). Generally, velvet bean can be fed to ruminant without involvement of any complicated problems. However, feeding velvet bean to poultry has been associated with reduction in overall growth performance (Harms et al., 1961; Ferriera et al., 2003). The reduction in overall growth performance in poultry has been attributed to the presence of anti nutritional factors in many varieties of the beans (Olaboro et al., 1991). One of these reported antinutrional factors is phytic acid. Many approaches have been used to minimize level of phytic acid in velvet bean such as roasting (Ferriera et al., 2003), soaking and more recently by using ultra-violet (UV) radiation (Kala and Mohan, 2011). Degradation of phyic acid in velvet bean by UV radiation has been reported to be dependent on exposure time (Kala and Mohan, 2011). However, this correlation magnitude and the kinetics of phytic acid degradation in velvet bean after being exposed to UV irradiation was not quantified. The objective of this study was to identify the correlation magnitude and the kinetics (i.e rate) of phytic acid degradation after exposing two accessions of velvet bean (for soaked and unsoaked seeds) to UV irradiation. This has practical application in estimating phytic acid content in velvet bean after exposure to UV radiation which is considered as an important antinutritonal factor in poultry nutrition.

\section{TREATMENTS AND DATA FITTING \\ 2.1.Treatments}

Velvet bean seeds (Mucuna pruriens (L.) DC var. utilis (Wall.ex Wight) Bak. ex Burck) were obtained as a source material. The treatment description and analysis of phytic acid of both seed accessions (black colored seed coat and white colored seed coat) were reported and obtained from 
previously published work described by Kala and Mohan (2011). Dry seeds of both accessions were placed in petridishes and exposed to UV-B light (15 W Philips lamp, Tempo Instruments and Equipment Pvt. Ltd, Bombay, India) for 10, 20, 30, 45, 60 and 90 minutes. The same treatments were also given to seeds of both the examined accessions soaked in distilled water for overnight. The overnight soaked seeds were dried at $55^{\circ} \mathrm{C}$. Both the raw and treated seeds were powdered in a Willey Mill to 60 mesh size. The effect of UV radiation on phytic acid content of the two velvet bean accessions obtained from previous work of Kala and Mohan (2011) and reported in (Table 1). The relatively small standard errors on the means (Table 1) indicate that the results are repeatable and the differences between the linearity of curves are of importance (Carlson and Poulsen, 2003). measure of the applicability of zero-order kinetics. Zero-order kinetics indicate the rate which is independent of the substrate concentration.

\section{RESULTS}

Simple regression analysis showed that the concentration of phytic acid after exposure of both accessions of velvet bean (with or without soaking) to UV irradiation was highly correlated and time dependent $\left(\mathrm{r}^{2}\right.$ ranged from 0.94 to 0.99$)$. In all treatments, the slope of the line indicates phytic acid degradation rate (i.e changing the concentration of phytic acid per unit time). Soaking white colored seed coat seeds before being treated by UV radiation showed a slightly higher phytic acid degradation rate (slope=3.2) (Fig. 1) compared to unsoaked seeds (slope=2.54) (Fig. 2). Regression analysis showed that soaking of white colored seed

Table (1): Effect of different UV radiation exposure period on phytic acid (mg/100 $\mathrm{g}$ ) of two accessions of VB (White colored seed coat and Black colored seed coat) (adapted from Kala and Mohan (2011).

\begin{tabular}{|c|l|l|l|l|}
\hline \multirow{2}{*}{$\begin{array}{c}\text { Time duration } \\
(\text { min) }\end{array}$} & \multicolumn{4}{|c|}{ Accessions } \\
\cline { 2 - 5 } & White colored seed coat & \multicolumn{1}{c|}{ Black colored seed coat } \\
\cline { 2 - 5 } & & With soaking** & No soaking & With soaking \\
\hline 0 & $483 \pm 0.41^{*}$ & $483 \pm 0.41$ & $634.12 \pm 0.78$ & $634.12 \pm 0.78$ \\
\hline 10 & $450.18 \pm 0.3$ & $440.33 \pm 0.21$ & $612.1 \pm 0.78$ & $600.36 \pm 0.75$ \\
\hline 20 & $424 \pm 0.18$ & $418.2 \pm 0.45$ & $592 \pm 1$ & $540.1 \pm 0.72$ \\
\hline 30 & $370.76 \pm 0.64$ & $350.16 \pm 0.19$ & $542.17 \pm 0.43$ & $510.2 \pm 0.43$ \\
\hline 45 & $342.16 \pm 0.54$ & $320.26 \pm 0.32$ & $510.36 \pm 0.94$ & $450.54 \pm 0.31$ \\
\hline 90 & $320.47 \pm 0.81$ & $240.12 \pm 0.42$ & $436.1 \pm 0.32$ & $360.24 \pm 0.6$ \\
\hline
\end{tabular}

* Means \pm SE $(\mathrm{n}=3)$.

** Soaking is conducted over night

\subsection{Data fitting}

For simplicity, simple linear regression was used to determine the rate of phytic acid degradation for both velvet bean accessions after being exposed to UV radiation at different durations (0 (raw seeds)),10, 20, 30, 45, 60 and 90 minutes). is given by equation (1)

$\mathrm{Y}=\mathrm{AX}+\mathrm{B}$

where $\mathrm{Y}$ is the phytic acid at time $\mathrm{X}$; $\mathrm{A}$ is the slope (rate of phytic acid degradation per unit time), and $\mathrm{X}$ is the exposure duration to UV Radiation.

For the purpose of data fitting, the value of $\mathrm{A}$ was obtained by linear-least-squares fit of the solution of eq. (1). The linearity of such a plot (indicated by correlation value) will provide a coat seeds over night increased rate of phytic acid degradation by $26 \%$. However, phytic acid degradation rate magnitude of black colored seed coat after soaking was different. Soaking black colored seed coat seeds before being treated by UV radiation showed a higher phytic acid degradation rate (slope=4.438) (Fig. 3) compared to unsoaked seeds (slope $=3.308$ ) (Fig. 4). Regression analysis (by comparing slopes) showed that soaking of black colored seeds coat seeds over night increased the rate of phytic acid degradation by $44 \%$.

Regression analysis of unsoaked seeds between the two accessions showed that black colored seed coat seeds hade a higher phytic acid degradation rate when compared to white colored seed coat 


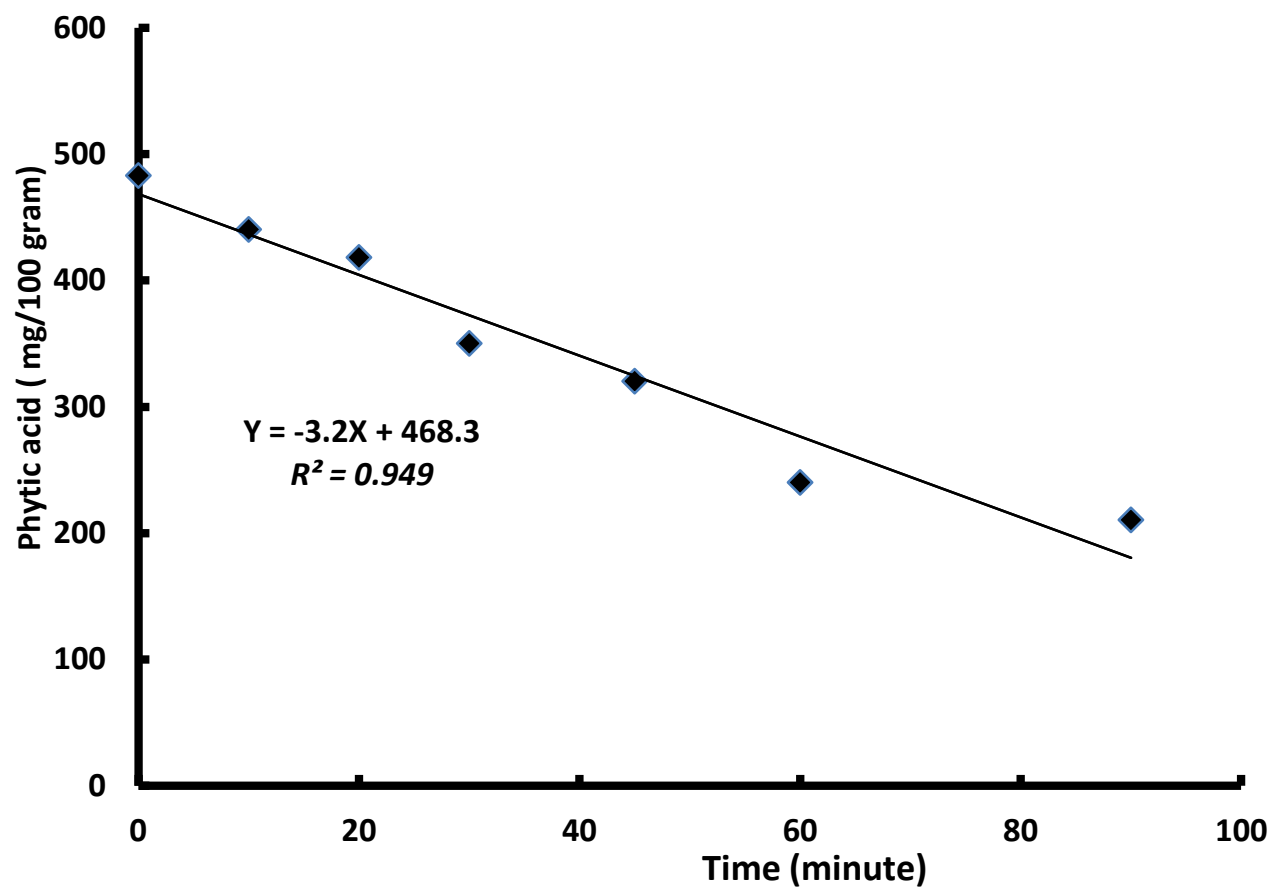

Fig. (1): Time dependence of phytic acid degradation of soaked white colored seed coat velvet beans after different exposure durations to UV radiation.

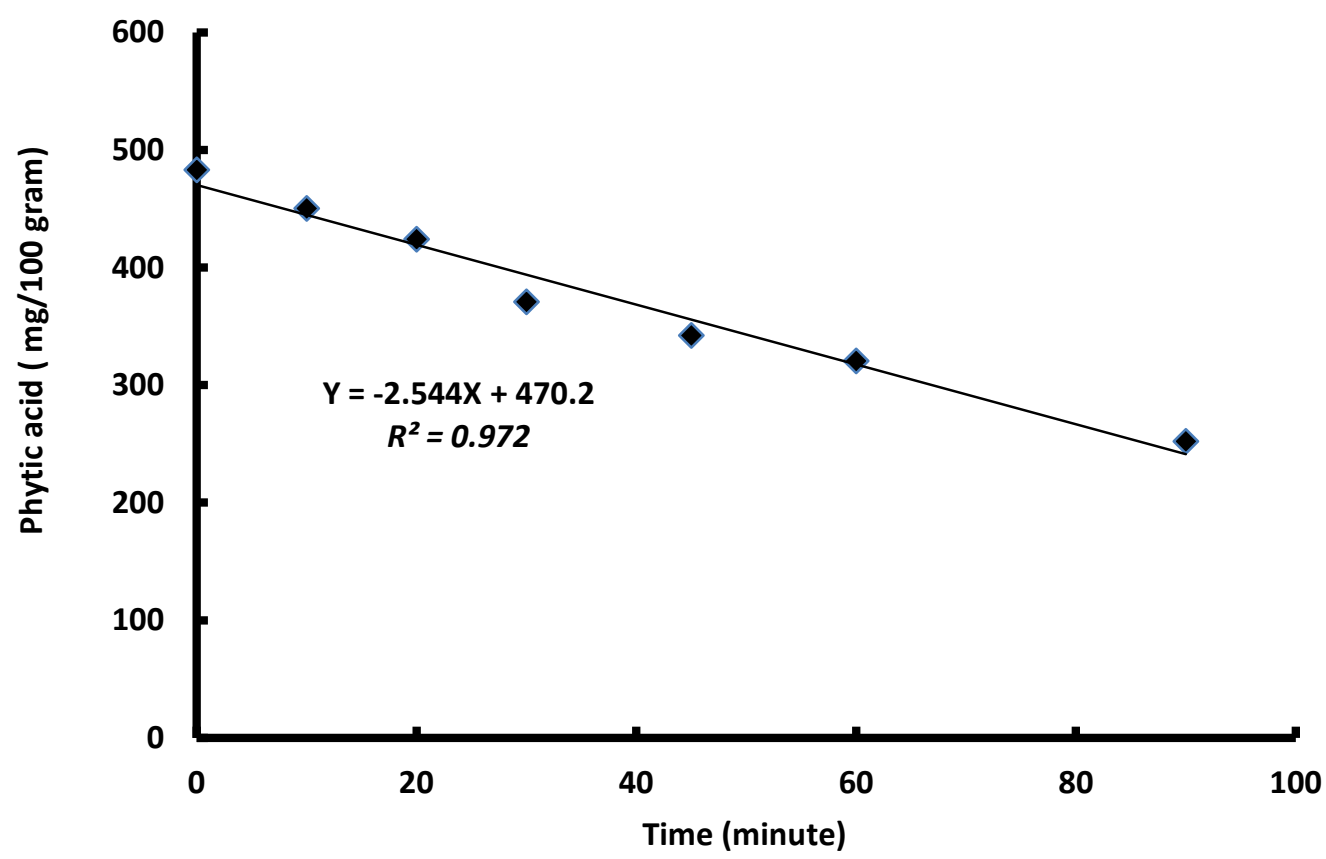

Fig. (2): Time dependence of phytic acid degradation of unsoaked white colored seed coat velvet beans after different exposure durations to UV radiation 


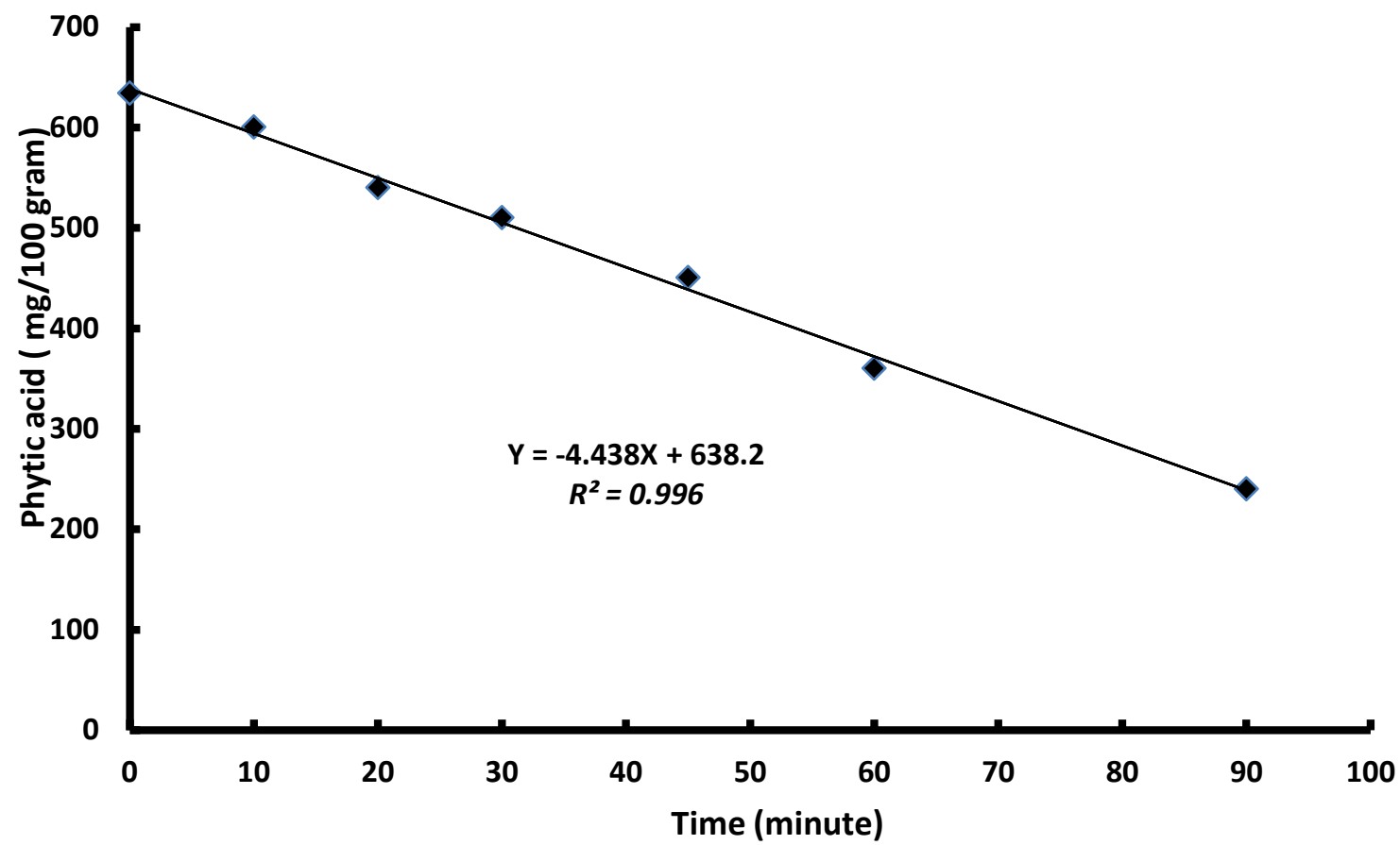

Fig. (3): Time dependence of phytic acid degradation of soaked black colored seed coat velvet beans after different exposure durations to UV radiation.

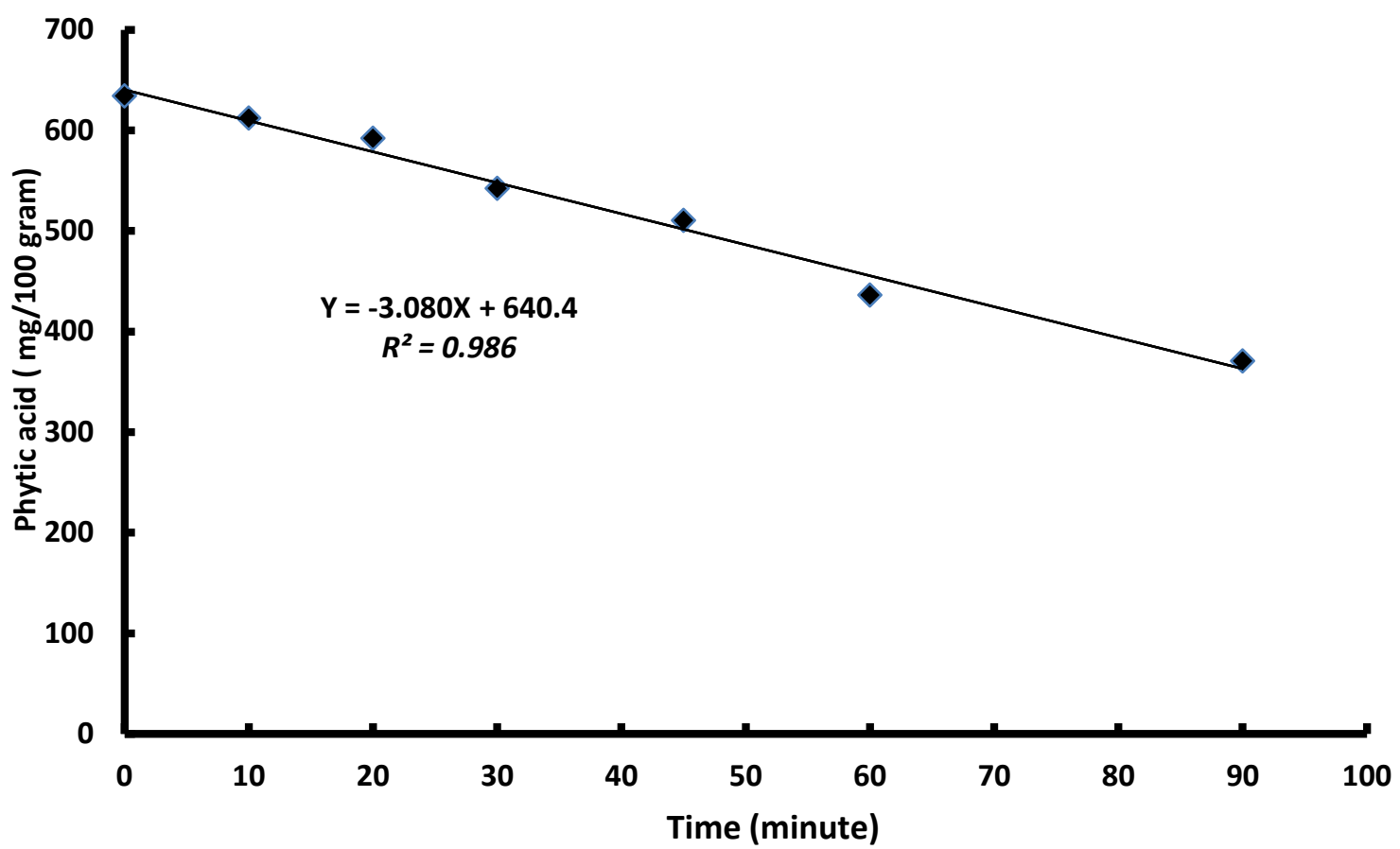

Fig. (4): Time dependence of phytic acid degradation of unsoaked black colored seed coat Velvet beans after different exposure durations to UV radiation. 
seeds (3.08 vs. 2.54, respectively) (Fig. 2 vs. 4). However, soaking seeds before being exposed to UV irradiation increased the degradation rate difference between the black colored seed coat and white colored seed coat (4.438 vs 3.2 , respectively) (Fig. 1 vs. Fig. 3).

\section{DISCUSSION}

The regression analysis was conducted in order to quantify the correlation and the degradation rate of phytic acid in two accessions of velvet bean after being treated by UV radiation. Fitting of the data indicates that the initial high concentration of phytic acid will not increase the rate of phytic acid degredation after being exposed to UV radiation. In other words, the amount of phytic acid degradation is proportional to the time being exposed to UV radiation treatment.

Soaking seeds in water and UV radiation treatment possesses different effect on phytic acid within seeds. Soaking seeds in water have been reported to enhance internal phytase activity (Carlson and Poulsen, 2003). However, UV radiation possesses different mode of action. UV radiation has been reported to reduce phytic acid by striking the free radicals produced through radiation which cause cleavage to phytic acid compound (DeBolland et al., 1975; Duodu et al. 1999). In both seed accessions, the higher degradation rate of phytic acid after seed soaking could be attributed to endogenous phytase activity that carried out phytic acid degradation over night before UV treatment take place. Selle and Ravindran (2007) reported that phytic acid content in poultry diet ranged from 0.89 to $1.424 \%$. Feeding poultry diets containing phytic acid higher than this level (i.e $1.57 \%$ ) has been reported to reduce overall poultry performance (Woyengo and Nyachoti, 2013). In their experiment (where the data were obtained), Kala and Mohan (2011) reported that the initial phytic acid concentration in white colored seed coat seed $(0.48 \%)$ and black colored seed coat seed $(0.634 \%)$ was lower than the level that reported to reduce overall poultry performance. Thus, it seems that presence of phytic acid in both accessions of velvet bean seems not to be the limiting antinutiriotnal factors that influence poultry performance. For that reason, it can be suggested that this concern must not be given due to the presence of phytic acid in velvet beans when formulating poultry diets. Presence of other antinutritional factors in velvet bean may determine the level of its inclusion in poultry diets. Vadivel and Janardhanan (2000) reported that velvet bean contains anti nutritional substances (like free phenolics compounds, tannins, L-DOPA, trypsin inhibitor activity and phytohaemagglutinating activity) which have nutritional significance if the beans were not properly processed. Soaked and roasted velvet bean have been reported to reduce feed intake and body weight gain of broiler when included in the diet at $20 \%$ inclusion level (Ferriera et al., 2003).

The difference in the rate of phytic acid degradation between the two accessions may be attributed to endogenous phytase activity in the two velvet beans accessions. However, phytase activity needed to be measured to confirm this since endogenous phytase activity in velvet beans was not investigated so far. Different seed accessions have been reported to posses different endogenous phytase activity in different feed stuff (Steiner et al., 2007) such as in wheat (Ram et al., 2010; OkotKotber et al., 2003), barley (Dai et al., 2010) and chickpea (Kaya and Küçükyumuk, 2009).

In conclusion, phytic acid degradation by UV radiation can be well fitted by zero-order kinetics for both soaked and unsoaked velvet bean accessions. Soaking before exposing seeds to UV radiation accelerated phytic acid degradation in both accessions. Comparing the harmful level of phytic acid on poultry performance that obtained from literature and the results obtained from linear regression analysis in this study, phytic acid in both accessions of velvet bean seems not to be the influential factor in determining its maximum inclusion level in poultry diets.

\section{REFERENCES}

Buckles D. (1995). Velvet bean: a "new" plant with a history. Economic Bot. 49:13-25.

Carlson D. and Poulsen, H. D. (2003). Phytate degradation in soaked and fermented liquid feed - effect of diet, time of soaking, heat treatment, phytase activity, $\mathrm{pH}$ and temperature. Ani. Feed Sci. and Technol. 103: 141-154.

Dai F., Qiu L., Xu Y., Cai S., Qiu B. and Zhang G. (2010). Differences in phytase activity and phytic acid content between cultivated and Tibetan annual wild barleys. J. Agri.e and Food Chemistry, 24: 11821-4.

DeBoland A. R., Garner G. B. and O’Bell B. L. 
(1975). Identification and properties of phytate in cereal seeds and oil seed products. J. Agric. Food Chemistry, 23:1186-1189.

Duodu K.G., Minnaar, A.and Taylor, J.R.N. (1999). Effect of cooking and irradiation on the labile vitamin and antinutrients content of traditional African sorgum porridge and Spinach relish. Food Chemistry, 66: 21-27.

Ezeagu I.E., Maziya-Dixon, B. and Tarawali, G. (2003). Seed characteristics and nutrient and antinutrient composition of 12 mucuna accessions from Nigeria. Tropical and Subtropical Agroecosystems, $1: 129$ - 139

Ferriera H.A., Peña, B.K., Gernat, A.G. Carew, L.B. and Matamoros I.A. (2003). Evaluation of different processing methods of velvet bean (Mucuna pruriens) for use as a feed ingredient for broilers. Tropical and Subtropical Agroecosystems, 1: 277 - 286.

Harms R.H, Charles, F. and Waldroup, P.W. (1961). Influence of feeding various levels of velvet beans to chicks and laying hens. J. Nutrition, 74: 127-131.

Kala B. K. and Mohan, V. R. (2011). Effect of UV treatment on the anti nutritional factors of two accessions of velvet bean Mucuna pruriens (L.) DC var. utilis ( Wall.ex Wight ) Bak. ex Burck. Tropical and Subtropical Agroecosystems, 15: 131-141.

Kaya M. and Küçükyumuk Z., I. (2009). Phytase activity, phytic acid, zinc, phosphorus and protein contents in different chickpea genotypes in relation to nitrogen and zinc fertilization. African J. Biotech., 8 (18), pp. 4508-4513.

Liener I. E. (1994). Implications of antinutritional components in soybean foods. Food Sci., 34:31-36.
Okot-Kotber M., Yong K., Bagorogoza K. and Liavoga, A. (2003). Phytase activity in extracts of flour and bran from wheat cultivars: enhanced extractability with $\beta$ glucanase and endo-xylanase. J. Cereal Scie., 8: 307-315.

Olaboro G., Okot M.W, Mugerwa J.S and Latshawa, J.D. (1991). Growth-depressing factors in velvet beans fed to broiler chicks. East African Agric. and Forestry J., 57:103 110.

Ram S., Verma A. and Sharma S. (2010). Large variability exits in phytase levels among Indian wheat varieties and synthetic hexaploids. J. Cereal Sci., 52, 486-490.

Selle P. H. and Ravindran, V. (2007). Review: Microbial phytase in poultry nutrition. Animal Feed Science and Technology, 135: $1-14$.

Steiner T., Mosenthin R., Zimmermann, B., Greiner, R. and Roth, S. (2007). Distribution of phytase activity, total phosphorus and phytate phosphorus in legume seeds, cereals and cereal by-products as influenced by harvest year and cultivar. Ani. Feed Sci., and Tech., 133: 320-334.

Vadivel V. and Janardhanan, K. (2000). Nutritional and anti-nutritional composition of velvet bean: an under-utilized food legume in south India. International J. Food Sci. and Nutr., 51(4):279-87.

Woyengo T. A. and Nyachoti C. M. (2013). Review: Anti-nutritional effects of phytic acid in diets for pigs and poultry_current knowledge and directions for future research. Canad. J. Anim. Sci., 93: 9-21. 


\section{ميكانيكية تحطم حمض الفايتك في صنفين من الفول المخملي ( Mucuna pruriens ) المعاملة بالأشعة فوق البنفجية}

$$
\begin{aligned}
& \text { مصطفى صالح الرو اشده - غيد جميل الربضي - نوفل العميريين*- فير اباهيو راماسامى مو هان** }
\end{aligned}
$$

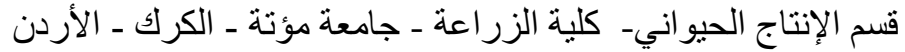

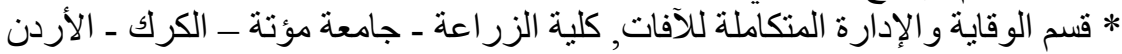

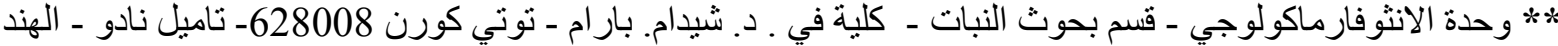

\section{ملخص}

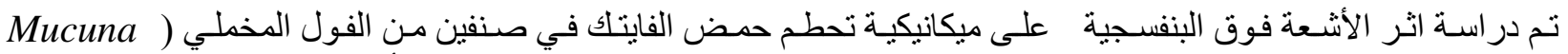
(قبriens

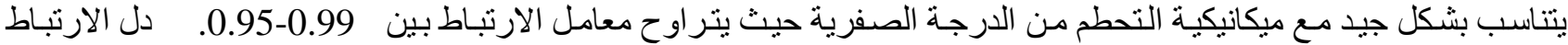

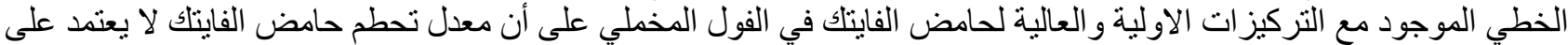

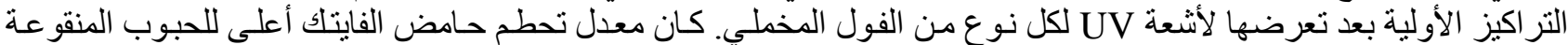

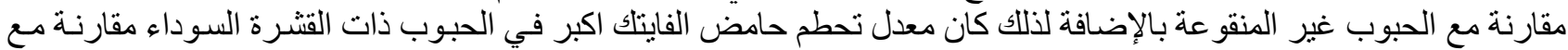

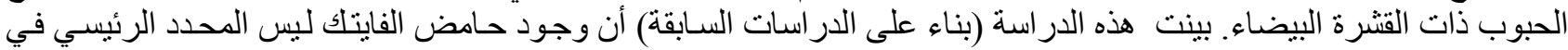

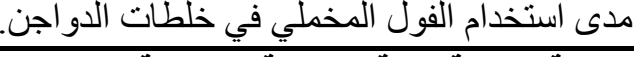
المجلة العلمية لكلية الزراعة - جامعة القاهرة - المجلا (64) العدد الرابع (أكتوبر2013):385-395. 